\title{
Relation between Ossicular Erosion and Destruction of Facial and Lateral Semicircular Canals in Chronic Otitis Media
}

\author{
Suphi Bulğurcu ${ }^{1}$ ilker Burak Arslan² Bünyamin Dikilitaşs ${ }^{2}$ ibrahim Çukurova² \\ 1 Department of Otorhinolaryngology, Başkale State Hospital, \\ Van, Turkey \\ 2 Department of Otorhinolaryngology, Tepecik Training and Research \\ Address for correspondence Suphi Bulğurcu, MD, Department of \\ Otorhinolaryngology, Başkale State Hospital, Başkale, Van, Van \\ Hospital, Izmir, Turkey
}

Int Arch Otorhinolaryngol 2017;21:239-242.

\begin{abstract}
Introduction Chronic otitis media can cause multiple middle ear pathogeneses. The surgeon should be aware of relation between ossicular chain erosion and other destructions because of the possibility of complications.

Objective This study aimed to investigate the rates of ossicular erosion in cases of patients with and without facial nerve canal destruction, who had undergone mastoidectomy due to chronic otitis media with or without cholesteatoma.

Methods We retrospectively analyzed three hundred twenty-seven patients who had undergone tympanomastoidectomy between April 2008 and February 2014. We documented the types of mastoidectomy (canal wall up, canal wall down, and radical mastoidectomy), erosion of the malleus, incus and stapes, and the destruction of facial and lateral semi-circular canal.

Results Out of the 327 patients, 147 were women (44.95\%) and 180 were men (55.04\%) with a mean age $50.8 \pm 13$ years (range $8-72$ years). 245 of the 327 patients (75.22\%) had been operated with the diagnosis of chronic otitis media with cholesteatoma. FNCD was present in 62 of the 327 patients (18.96\%) and 49 of these 62 (79.03\%) patients had chronic otitis media with cholesteatoma. The correlation

Keywords

- ear ossicles

- facial nerve

- otitis between the presence of FNCD with LSCC destruction and stapes erosion in chronic otitis media with cholesteatoma is statistically significant $(p<0.05)$.

Conclusion Although incus is the most common of destructed ossicles in chronic otitis media, facial canal destruction is more closely related to stapes erosion.
\end{abstract}

\section{Introduction}

Chronic otitis media (COM) can cause disruption in the continuity of the ossicular chain as well as other destructions especially in the cholesteatoma cases. This pathology may be limited to the incudostapedial joint, but usually total or partial loss of the long process of the incus can be seen as well. ${ }^{1}$ Saurabh Varshney et al have reviewed 150 cases and have found malleus, incus, and stapes intact in 121 (80.67\%), 92 (61.33\%), and 118 (78.67\%) cases, respectively. ${ }^{2}$

Chronic otitis media causes destruction of the facial nerve canal (FNCD) and lateral semicircular canal (LSCC) in time. Facial nerves become more vulnerable without their bony coverage. $^{3}$ Destruction is more common in the tympanic segment, especially in the neighboring tissues of the oval window, but may also occur in the geniculate ganglion and received

June 19, 2016

accepted

August 14, 2016

published online

September 14, 2016
DOI https://doi.org/

10.1055/s-0036-1592417. ISSN $1809-9777$.
Copyright (e 2017 by Thieme Revinter

Publicações Ltda, Rio de Janeiro, Brazil
License terms

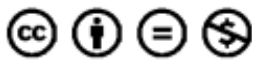


even in the vertical segment. The frequency of intraoperative facial canal dehiscence varied from $0.5 \%$ to $33 \%$ in this study. 2,4

The labyrinthine dehiscence is a rare complication of COM and usually caused by cholesteatoma. In nearly $90 \%$ of patients, the labyrinthine fistula is located in the LSCC. Preoperative diagnosis with CT is useful, but the verification of a labyrinthine dehiscence can only be definitely established at the time of surgery. 5,6

In this study, we investigated the difference of rates between ossicular erosion in cases of patients with and without FNCD/LSCC who had undergone mastoidectomy due to chronic otitis media with or without cholesteatoma.

\section{Methods}

We retrospectively analyzed the surgery records of 327 patients who had experienced tympanomastoidectomy between April 2008 and February 2014. We documented the type of mastoidectomy (canal wall up, canal wall down, and radical mastoidectomy), information about the ossicular erosion, the destruction of facial, and LSCC in patients who were operated due to chronic otitis media with or without cholesteatoma. We excluded patients with temporal bone fracture or temporal bone neoplasm, tympanoplasty without mastoidectomy, revision surgery, stapes surgery for otosclerosis, or explorative tympanotomy.

We analyzed the ossicular chain erosion by inspection under direct high magnification. We investigated destruction of the facial nerve canal and LSCC through direct inspection under high magnification using the operation microscope, and through palpation with a blunt pick.

We classified FNCD as involving the labyrinthine, tympanic, and mastoid segments.

We divided the patients into two groups: 1) patients with cholesteatoma, 2 ) patients without cholesteatoma. In both groups, we compared the destruction of the facial canal and other intraoperative findings (destruction of ossicular chain and LSCC). We also compared such findings (destruction of facial canal, ossicular chain, and LSCC) between the two groups. We performed statistical analysis using SPSS 20.0 software (SPSS Inc., Chicago, IL, USA). We tested the statistical significance of differences between paired groups using the chi-squared test and defined significance as $p<0.05$.

\section{Results}

Out of the 327 patients, 147 were women (44.95\%) and 180 were men $(55.04 \%$ ) with a mean age $50.8 \pm 13$ years (range 8-72 years). From this sample, 179 patients had undergone canal wall down mastoidectomy, 94 patients had undergone intact canal mastoidectomy, and 54 patients had undergone radical mastoidectomy. Moreover, 245 of the $82(25.07 \%)$ had been operated with the diagnosis of chronic otitis media without cholesteatoma (chronic mucosal disease, tympanosclerosis, and adhesive otitis without cholesteatoma) and 327 patients (75.22\%) had been operated with the diagnosis of chronic otitis media with cholesteatoma.

FNCD was present in 62 of the 327 patients (18.96\%). Forty-nine of these 62 (79.03\%) were chronic otitis media patients with cholesteatoma and 13 patients were chronic otitis media without cholesteatoma. Among the patients with FNCD, there was mere involvement of the tympanic segment in 59 (95.16\%), involvement of the tympanic and the mastoid segments in one (1.61\%), and involvement of solely the mastoid segment in two (3.22\%). - Table 1 shows rates of ossicular chain erosion and lateral semicircular canal destruction in all cases and cases with FNCD. Rates of ossicular chain erosion and lateral semicircular canal destruction in chronic otitis media with and without cholesteatoma together with the subgroup of with and without FNCD are shown in -Table 2.

The correlation between the presence of FNCD with lateral semi-circular canal destruction and stapes erosion in chronic otitis media with cholesteatoma is statistically significant $(p<0.05)$ (-Table 2 ).

Frequencies of mastoidectomy types in chronic otitis media with and without cholesteatoma together with the subgroups with and without FNCD are shown in - Table 3.

The correlation between the presence of FNCD and radical mastoidectomy operation in chronic otitis media with cholesteatoma is statistically significant $(p<0.05)$ ( - Table 3 ).

\section{Discussion}

The maturation of the facial nerve canal begins at 21 gestational weeks from apical otic ossification centers and at 26 gestational weeks from canalicular ossification centers next to the stapedial muscle. The two centers fuse postpartum next to the region of the oval window. Nevertheless, it is not

Table 1 Rates of ossicular chain erosion and lateral semicircular canal destruction in all cases and cases with facial nerve canal destruction

\begin{tabular}{|l|l|l|}
\hline & All cases (327) & Cases of facial nerve canal destruction (62) \\
\hline Frequency of intacts malleus & $56.26 \%(184)$ & $48.38 \%(30)$ \\
\hline Frequency of intacts incus & $9.17 \%(30)$ & $3.22 \%(2)$ \\
\hline Frequency of intacts stapes & $44.03 \%(144)$ & $29.03 \%(18)$ \\
\hline Frequency of LSCC destruction & $4.58 \%(15)$ & $9.67 \%(6)$ \\
\hline
\end{tabular}

Abbreviations: LSCC, Lateral semi-circular canal.

The numbers between parentheses show the number of patients. 
Table 2 Rates of ossicular chain erosion and lateral semicircular canal destruction in chronic otitis media with and without cholesteatoma together with the subgroups with and without facial nerve canal destruction

\begin{tabular}{|l|l|l|l|l|}
\hline \multirow{2}{*}{} & \multicolumn{2}{|l|}{ Chronic otitis with cholesteatoma } & \multicolumn{2}{l|}{$\begin{array}{l}\text { Chronic otitis without } \\
\text { cholesteatoma }\end{array}$} \\
\cline { 2 - 5 } & FNCD $(+)(49)$ & FNCD(-)(196) & FNCD(+)(13) & FNCD(-)(69) \\
\hline Frequency of intacts malleus & $46.93 \%(23)$ & $53.57 \%(105)$ & $61.53 \%(8)$ & $72.46 \%(50)$ \\
\hline Frequency of intacts incus & $2.04 \%(1)$ & $5.61 \%(11)$ & $7.69 \%(1)$ & $24.63 \%(17)$ \\
\hline Frequency of intacts stapes & $24.48 \%(12)$ & $40.81 \%(80)$ & $46.15 \%(6)$ & $66.66 \%(46)$ \\
\hline
\end{tabular}

Abbreviations: FNCD, Facial nerve canal destruction; LSCC, Lateral semi-circular canal.

The numbers between parentheses show the number of patients.

Table 3 Correlation between the presence of facial nerve canal destruction and radical mastoidectomy operation in chronic otitis media with cholesteatoma

\begin{tabular}{|l|l|l|l|l|}
\hline \multirow{2}{*}{} & \multicolumn{2}{l|l|}{ Chronic otitis with cholesteatoma } & \multicolumn{2}{l}{$\begin{array}{l}\text { Chronic otitis without } \\
\text { cholesteatoma }\end{array}$} \\
\cline { 2 - 5 } & FNCD(+)(49) & FNCD(-)(196) & FNCD(+)(13) & FNCD(-)(69) \\
\hline Frequency of CWD mastoidectomy & $63.26 \%(31)$ & $67.34 \%(132)$ & $46.15 \%(6)$ & $14.49 \%(10)$ \\
\hline Frequency of intact canal mastoidectomy & $2.04 \%(1)$ & $16.83 \%(33)$ & $38.46 \%(5)$ & $79.71 \%(55)$ \\
\hline Frequency of radical mastoidectomy & $34.69 \%(17)$ & $15.81 \%(31)$ & $15.38 \%(2)$ & $5.79 \%(4)$ \\
\hline
\end{tabular}

Abbreviations: CWD, Canal wall down; FNCD, Facial nerve canal destruction.

The numbers between parentheses show the number of patients.

evident when the facial nerve canal has totally developed. There is a report that the development of the canal was completed by the age of four years from an anatomical and radiological stand point. In early childhood, middle ear inflammations may barely influence the development of the facial canal. ${ }^{7}$

Almost surgical reports regarding facial canal destruction have been conducted commonly with patients who have undergone chronic otitis surgery with or without cholesteatoma. ${ }^{8}$ The incidence of facial canal destruction ranges from $0.5 \%$ to $74 \%$, and is mostly higher in histologic studies than in surgical studies. This result may be due to the destruction of the bone covering the facial nerve while processing the cadaver, or preparation of the temporal bone. ${ }^{9}$ While facial canal dehiscences may be developmental due to inadequate ossification of the bony canal, they may also arise from resorption caused by chronic otitis media, with or without cholesteatoma.

Patients, who had involvement of multiple ossicles generally had significant cholesteatoma inside the tympanic cavity such that $85 \%$ of patients with damage to the incus and stapes showed cholesteatoma of the tympanic sinus, facial recess, oval window, and round window. $^{10}$

Complications such as peripheral facial paralysis and labyrinthine fistulas were occurred more frequently in patients with otitis media with cholesteatoma rather than otitis media with noncholesteatoma. We preferred to use the term canal destruction instead of canal dehiscence, because every case in this article had chronic otitis media. Although the mechanism of paralysis as a result of chronic otitis media is not fully understood, FNCD could be an underlying factor in the development of facial palsy. Also chronic otitis media can cause destruction of LSCC. The incidence of labyrinthine fistulas secondary to chronic otitis media in the modern literature varies from 3 to 13 percent. ${ }^{11}$

We determined that when FNCD was observed in mastoidectomy operation for chronic otitis media with cholesteatoma, the increase of the frequency of stapes erosion was more than the other ossiculars. Although in these operations the number of incus erosion was higher than in others, only an increase of the frequency of stapes erosion was statistically significant. Thus, once stapes erosion in mastoidectomy operation is established, the surgeon should take greater care because of the possibility of facial nerve injury.

\section{Conclusion}

The aim of this study is to indicate that stapes erosion is established in greater proportion to other ossicles in FNCD with mastoidectomy operations and to assert that the surgeon must be more careful because of the possibility of facial nerve injury when stapes erosion in mastoidectomy operations is established. Accidental injury may result in facial nerve damage if the surgeon does not pay enough attention to the site where the bony defects of the facial canal are frequently expected to present. Risk of destruction in facial and labyrinthine canal increased in a patient who had undergone radical or CWD tympanoplasty. 
Surgeons must be alert to facial and labyrinthine canal destruction when they decide radical mastoidectomy or CWD tympanoplasty.

\section{References}

1 El-Kashlan HK, Harker LA. In: Cummings otolaryngology, head and neck surgery. 4th ed. Cummings CW, Flint PW, Harker LA, Haughey BH, Richardson MA, Robbins

2 Varshney S, Nangia A, Bist SS, Singh RK, Gupta N, Bhagat S. Ossicular chain status in chronic suppurative otitis media in adults. Indian J Otolaryngol Head Neck Surg 2010;62(4): 421-426

3 Yetiser S. The dehiscent facial nerve canal. Int J Otolaryngol 2012; 20(2012):679708

4 Lin JC, Ho KY, Kuo WR, Wang LF, Chai CY, Tsai SM. Incidence of dehiscence of the facial nerve at surgery for middle ear cholesteatoma. Otolaryngol Head Neck Surg 2004;131(4): 452-456
5 Jia M, Qin Z. Diagnosis and surgical management of labyrinthine fistula caused by cholesteatoma. Lin Chuang Er Bi Yan Hou Ke Za Zhi 2005;19(13):592-593

6 Payal G, Pranjal K, Gul M, Mittal MK, Rai AK. Computed tomography in chronic suppurative otitis media: value in surgical planning. Indian J Otolaryngol Head Neck Surg 2012;64(3):225-229

7 Nomiya S, Kariya S, Nomiya R, et al. Facial nerve canal dehiscence in chronic otitis media without cholesteatoma. Eur Arch Otorhinolaryngol 2014;271(3):455-458

8 Genc S, Genc MG, Arslan IB, Selcuk A. Coexistence of scutum defect and facial canal dehiscence. Eur Arch Otorhinolaryngol 2014;271(4):701-705

9 Kim CW, Rho YS, Ahn HY, Oh SJ. Facial canal dehiscence in the initial operation for chronic otitis media without cholesteatoma. Auris Nasus Larynx 2008;35(3):353-356

10 Mohammadi G, Naderpour M, Mousaviagdas M. Ossicular erosion in patients requiring surgery for cholesteatoma. Iran J Otorhinolaryngol 2012;24(68):125-128

11 Harker LA, Pignatari SS. Facial nerve paralysis secondary to chronic otitis media without cholesteatoma. Am J Otol 1992; 13(4):372-374 